\title{
Study on the Education Curriculum and Clinical Practice of Medical Technologists
}

Byoung-Seon Yang ${ }^{1}$, Se-Mook Choi ${ }^{1}$, Moon-Jung Shim ${ }^{2}$, Chung-Hwan Kim ${ }^{3}$, Hyung-Joon Bae ${ }^{4}$, Keun-Dol Yook ${ }^{5}$, Yoon-Sik Kim ${ }^{6}$, Yong Lim ${ }^{7}$, Ji-Hyuk Kang 8 , Hong-Sung Kim 9 , Dong-Chan Kim ${ }^{10}$, Gyeonghee Shin ${ }^{11}$, Sang-Hee Lee ${ }^{12}$

\author{
${ }^{1}$ Department of Medical Laboratory Science, Jinju Health College, Jinju, Korea \\ ${ }^{2}$ Department of Clinical Laboratory Science, Ansan University, Ansan, Korea \\ ${ }^{3}$ Department of Biomedical Laboratory Science, Masan University, Masan, Korea \\ ${ }^{4}$ Department of Clinical Laboratory Science, Daejeon Institute of Science and Technology, Daejeon, Korea \\ ${ }^{5}$ Department of Clinical Laboratory Science, Daejeon Health Institute of Technology, Daejeon, Korea \\ ${ }^{6}$ Department of Biomedical Laboratory Science, Dongkang College University, Gwangju, Korea \\ ${ }^{7}$ Department of Clinical Laboratory Science, Dong-eui University, Busan, Korea \\ ${ }^{8}$ Department of Biomedical Laboratory Science, DaeJeon University, Daejeon, Korea \\ ${ }_{9}^{9}$ Department of Medical Laboratory Science, Korea Nazarene University, Cheonan, Korea \\ ${ }^{10}$ Seoul National University Hospital Healthcare System Gangnam Center, Seoul, Korea \\ ${ }^{11}$ Department of Laboratory Medicine, Korea University Anam Hospital, Seoul, Korea \\ ${ }^{12}$ Department of Laboratory Medicine, Asan Medical Center, Seoul, Korea
}

\section{임상병리사 교육과정 및 임상실습에 대한 연구}

\author{
양병선 ${ }^{1}$, 최세묵 ${ }^{1}$, 심문정 ${ }^{2}$, 김충환 $^{3}$, 배형준 $^{4}$, 육근돌 $^{5}$, 김윤식 $^{6}$, 임 용 $^{7}$, 강지혁 $^{8}$, 김홍성 $^{9}$, 김동찬 $^{10}$, 신경희 $^{11}$, \\ 이상희 ${ }^{12}$ \\ ${ }^{1}$ 진주보건대학교 임상병리과, ${ }^{2}$ 안산대학교 임상병리과, ${ }^{3}$ 마산대학교 임상병리과, ${ }^{4}$ 대전과학기술대학교 임상병리과, ${ }^{5}$ 대전보건대학교 임상병리과, \\ ${ }^{6}$ 동강대학교 임상병리과, ${ }^{7}$ 동의대학교 임상병리학과, ${ }^{8}$ 대전대학교 임상병리학과, ${ }^{9}$ 나사렛대학교 임상병리학과, ${ }^{10}$ 서울대학교병원 헬스케어시스템 강남센터, \\ ${ }^{11}$ 고려대학교병원 안암병원 진단검사의학과, ${ }^{12}$ 서울아산병원 진단검사의학과
}

\begin{abstract}
This study analyzed the curriculum and clinical practicum of the department of clinical laboratory science in Korea. The 2017 educational curricula of all 3-year and 4-year universities were analyzed. Clinical practice was conducted by a questionnaire. As a result of curriculum analysis, the 3-year curriculum was able to grasp the curriculum that focused on the national examinations of medical technologists, and the 4-year curriculum was open to a variety of subjects reflecting the changes in the future, but only at a few universities. In addition, the autonomous enrollment application made it possible to take a national examination without enrolling in courses that students find difficult in major courses. In the case of clinical practice, it was difficult to standardize in various practical institutes, practice periods, and practice credits. Therefore, it will be necessary to standardize the composition of the credits according to the duration of clinical practice and the duration of education. Moreover, is necessary to revise the curriculum in consideration of medical technologist job analysis and clinical field, and it will be necessary to standardize the curriculum and clinical practice model through the Medical Technologist Evaluation Center.
\end{abstract}

Key words: Clinical practice, Education curriculum, Medical technologist

This is an Open Access article distributed under the terms of the Creative Commons Attribution Non-Commercial License (http://creativecommons.org/licenses/by-nc/4.0) which permits unrestricted non-commercial use, distribution, and reproduction in any medium, provided the original work is properly cited.

Copyright () 2018 The Korean Society for Clinical Laboratory Science. All rights reserved.
Corresponding author: Byoung-Seon Yang Department of Medical Laboratory Science, Jinju Health College, 51 Uibyeong-ro, Jinju 52655, Korea

Tel: 82-55-740-1821

Fax: 82-55-743-3010

E-mail: ybseon@jhc.ac.kr

Received: July 16, 2018

Revised: August 3, 2018

Accepted: August 7, 2018 


\section{서 론}

우리나라의 임상병리사에 대한 대학교육과정의 시작은 1963년 수도의과대학에 의학기술초급대학에 2년제 임상병리 과의 개설이었다. 이 후 1965 년 제 1 회 임상병리사 국가고시가 실시되었고 같은 해 사단법인 대한임상병리사협회가 창립되었 다[1]. 이 후 의료기술과 진단수준의 급격한 발전과 확대가 일어 났으며 이는 대학의 대대적인 임상병리(학)과 증설로 이어졌다. 발전된 임상병리사의 업무내용과 사회의 변화와 함께 임상병리 교육도 많은 변화를 거듭해 왔다. 교육기관의 학제도 변화에 부 응하여 1991년 3년제로 교육제도가 개편되었다[2]. 4년제 교 육기관은 1979년 연세대학교 원주캠퍼스 의과대학에 보건학 과가 설립되어 학과 내에 임상병리기술학 전공과정으로 교육되 었으며 1987년에 보건학과가 보건대학으로 승격되면서 4년제 임상병리학과가 처음 설립되었다[1]. 현재는 3년제 대학이 25 개 대학, 4 년제 대학이 25 개 대학에 이르렀으며 학제는 이원화 되어 있는 상태이다. 8개 4년제 대학에서는 대학원 과정을 개설 하여 변화하는 사회에 맞추어 대응하고 있다. 의학과 과학의 눈 부신 발달로 인하여 임상병리사가 되기 위해서는 더 많은 지식 과 실기능력이 요구되고 있는 것이 현실이다. 임상병리사를 양 성하는 대학의 교육 역시 단순한 정보제공이나 지식의 전달정 도에서 문제해결능력을 배양해야하는 수준으로, 학문 단위 중 심에서 통합적인 주제 중심으로 더 체계적인 교육이 필요하게 되었다. 또한 보건의료분야에서 전문화의 움직임은 새로운 과 학기술과 지식의 발달, 경제수준의 향상, 노인관련 의료분야의 증가, 건강관리 패턴의 다양화를 배경으로 의료관련 직종의 세 분화와 의료소비자의 요구도 상승, 선진국의 전문화 추세와 맞 물려 발달의 촉진요소가 되었다. 이에 발맞추어 현대의 임상병 리사 업무범위는 지금의 범위에 국한되지 않고 더욱 넓어질 것 이며, 그에 따른 새로운 검사법들이 앞으로도 계속적으로 개발 되어질 것이고, 또한 새로운 검사기기 등이 검사현장에 도입될 것은 당연한 일이다. 이러한 의료기술(medical technology)의 발전과 세계화 추세는 질 높은 임상병리 업무수행능력과 해결 능력을 요구하고 있는데 3년제 전문대학 전문학사과정과 4년 제 학사과정으로 이원화되어 적절한 대처를 하지 못하고 있는 것이 현실이다. 이원화된 교육기관에서 배출된 학생들은 겉으 로는 같은 교육과정을 이수하고 같은 국가고시를 치러 같은 면 어를 취득하여 같은 산업체에서 같은 일을 하지만, 속으로는 이 임상병리사들이 같은 직장에서 같은 일을 하면서도 학제의 다 름 때문에 겪는 여러 불만과 갈등이 생길 수밖에 없는 구조를 내 포하고 있다. 이러한 구조 때문에 초래된 불만과 갈등에 의해 양
질의 임상병리 업무에 많은 지장과 손실이 일어남으로써 질적 인 임상병리교육을 추구하기 위한 노력과는 상반된 교육이 일 어나고 있다. 이러한 현상은 지금은 모두 4년제로 일원화된 간 호학과에서도 예전에 3년제와 4년제로 이원화 되어있었을 때 겪었던 문제인데 지금 학제가 4년제로 단일화 되면서 해결되었 다고 볼 수 있다 33,4$]$. 임상병리학과에서는 특히 3년제 교육과 정의 학생은 급변하는 임상병리분야의 발전과 변화를 습득하고 산업체에 적용하기에는 면허취득공부를 하는 것만으로도 시간 의 부족함을 느끼고 있는 실정이다. 또한 임상실습에 있어서도 3 년제와 4년제 교육기관에서는 각각 2학년 때와3학년 때에 산 업체로 임상실습을 이수하도록 하고 있는데 각 대학마다 학점 과 실습기간 등이 다르고 임상실습에 대한 여러 문제점과 산업 체와 대학의 의견조사도 부족한 실정이다. 우리나라의 임상병 리사의 발전과 변화에 발을 맞추어 대학들 또한 2년제 교육과정 에서 3 년제 교육과정으로, 4 년제 교육과정을 운영하는 대학은 대학원과정을 개설하는 등 그 변화와 발전의 속도를 맞추기 위 하여 노력하여 왔다. 최근의 임상병리분야의 발전은 더욱 빠른 속도로 발전하고 있다. 2 년제에서 3 년제로 변화하는데 28 년의 시간이 걸렸고 3 년제를 운영한지 26 년의 시간이 흘렀다. 이즈 음에 우리나라 학제의 교육과정을 살펴볼 필요가 산업체 전반 에서 요구되고 있다. 또 임상실습에 있어서도 전국 모든 임상병 리학과에서 실무형 인재를 양성하기 위하여 필수적으로 시행하 고 있는데 임상실습교육의 시기, 기관, 내용, 운영 및 평가 등 현 행 임상실습교육의 문제점을 도출하고, 개선방향을 제안하여 표준화방안을 모색하기 위한 기초자료를 확보하고자 한다. 산 업체는 현장중심의 실무형 인재를 요구함과 동시에 4 차 산업혁 명이라는 큰 물결 속에 임상병리분야의 발전에 부응할 수 있는 우수한 임상병리사를 요구하고 있다. 이에 본 연구에서는 3 년제 교육과정, 4년제 교육과정, 임상실습현황, 해외 교육과정을 조 사 분석하여 급변하는 우리나라의 임상병리분야에 대처할 수 있는 정책의 기초 자료를 제공하고자 한다.

\section{재료 및 방법}

\section{3년제 25개교 교육과정 조사}

전국 25개 3년제 대학에 2017학년도 교육과정을 요청하여 전수 조사하였다.

\section{4년제 25 개교 교육과정 조사}

전국 25개 4년제 대학에 2017학년도 교육과정을 요청하여 전수 조사하였다. 


\section{3. 임상실습 현황 조사}

임상실습의 시행시기, 임상실습성적의 교육과정반영에 관 한사항, 임상실습교육 기관, 임상실습교육의 내용 및 운영에 관 한 사항 등 임상실습의 문제점을 구체화하고, 표준화의 방향을 도출하기 위하여 대학용, 산업체용으로 구분하여 설문문항을 작성하였다. 특히 표준화 방안의 기초자료로 활용하기 위하여 현행의 문제점을 토대로 개선방향을 모색할 수 있는 문항으로 구성하였고, 2016년 한국보건의료인국가시험원 연구과제 '우 수한 임상병리사 양성 및 배출을 위한 정책제안 연구'에서 임상 실습 분야에 대해 연구한 내용[5]을 기반으로 조금 더 구체화시 킬 수 있는 세부사항에 대하여 설문조사결과를 얻고자 하였다.

- 설문방법 : 문자발송 $\rightarrow$ 스마트폰 $\rightarrow$ 네이버설문지접속

- 설문기간 : 2018. 1.18 2018. 1. 25.

- 설문문자발송수 : 대학용 260건, 산업체용 11,738 건

- 설문문자회신수 : 대학용 76 건, 산업체용 1,142 건

\section{4. 해외 교육과정 분석}

문헌조사와 American Society of Clinical Pathology (ASCP), National Accreditating Agency for Clinical Laboratory Sciences (NAACLS), Canidian Society of Medical Laboratory Science (CSMLS), Australia Institute of Medical Scientist (AIMS) 홈페이지, 그리고 미국, 캐나다, 호주 등의 임상병리학 프로그램이 개설된 대학 홈페이지를 참조하여 면허증과 자격증을 획득 할 수 있는 기본교육요건과 교육과정 을 조사하였다.

\section{결 과}

\section{3년제 25 개교 교육과정 분석}

전국 임상병리과가 설치된 3년제 대학은 총 26개교로 이중 A 대학의 경우는 2017년 학생을 모집하지 않은 대학으로 이번 연 구에는 제외하고 총 25 개교를 분석하였다. 교육과정은 2017학 년도 교육과정을 중심으로 분석하였으며, 분석은 대학학점 구 성 및 비율, 주 전공 교과목 학점 비율, 주 전공교과목 이론 및 실 습 비율, 주 교과 분야별 구성 교과목수, 교육과정 편성 비율, 중
요과목 학기별 분포 등을 분석하였다. 분석의 어려운 점은 대학 마다 교과목의 명칭이 다양한 것, 전공기초과목이 교양과목으 로 분류되는 대학도 있었다는 것, 교과목명을 세미나 I, II 등으 로 표기하여 학문분야를 파악하기 어려운 과목도 있었다는 것 등이었다.

\section{1) 대학 학점 구성 및 비율}

대학의 평균학점을 분석하면 전공기초분야 26학점(22\%), 조직병리학분야 14.4 학점(12\%), 혈액학분야 13.2 학점(11\%), 임상화학분야 15.6 학점(14\%), 미생물학분야 20.4학점(18\%), 임상생리학분야 14.2 학점(12\%), 공중보건학 2.8 학점(3\%), 보 건의료법규 2.6학점(2\%), 임상실습 6.9학점(6\%)으로 구성되었 다(Tables 1, 2).

\section{2) 주 전공 교과목 학점 비율}

주 전공교과목인 조직병리학분야, 혈액학분야, 임상화학, 미 생물학분야, 임상생리학분야의 비율을 보면, 가장 높은 분야는 미생물학으로 $26 \%$, 다음은 임상화학분야 $20 \%$, 조직병리학 $19 \%$, 임상생리학 $18 \%$, 혈액학 $17 \%$ 순으로 나타났다.

\section{3) 주 전공교과목 이론 및 실습 비율}

주 전공교과목 이론 및 실습 비율을 보면, 임상화학분야 이론

Table 1. Medical technologist* national examination

\begin{tabular}{cl}
\hline & \multicolumn{1}{c}{ Examination subjects } \\
\hline Theory I & - Health and medical law \\
& - Public health \\
& - Anatomy and physiology \\
& - Histopathology (including cytology) \\
& - Clinical physiology (including Cardiopulmonary \\
& physiology, Neurophysiology, Others) \\
Theory II & - Clinical chemistry (including urine chemistry, \\
& nuclear medicine in vitro technology) \\
& - Clinical microbiology (including mycology, virology, \\
& parasitology, immunoserology) \\
Practice & - Clinical hematology (including transfusionology) \\
& - Clinical laboratory testing
\end{tabular}

*Synonyms: Medical laboratory technologist, Clinical laboratory technologist, Medical laboratory scientist, Clinical laboratory technologist.

Source: Korea Health Personnel Licensing Examination Institute.

Table 2. Average credits and percent by courses

\begin{tabular}{cccccccccc}
\hline Field & $\begin{array}{c}\text { Basic } \\
\text { subjects }\end{array}$ & Histopathology & Hematology & $\begin{array}{c}\text { Clinical } \\
\text { chemistry }\end{array}$ & Microbiology & $\begin{array}{c}\text { Clinical } \\
\text { Physiology }\end{array}$ & $\begin{array}{c}\text { Public } \\
\text { health }\end{array}$ & $\begin{array}{c}\text { Health and } \\
\text { medical law }\end{array}$ & $\begin{array}{c}\text { Clinical } \\
\text { practicum }\end{array}$ \\
\hline Credits (\%) & $26(22)$ & $14.4(12)$ & $13.2(11)$ & $15.6(14)$ & $20.4(18)$ & $14.2(12)$ & $2.8(3)$ & $2.6(2)$ & $6.9(6)$ \\
\hline
\end{tabular}


$53 \%$, 실습 $47 \%$; 혈액학분야 이론 $50.1 \%$, 실습 $49.9 \%$; 미생물 학분야 이론 $54.6 \%$, 실습 $45.4 \%$; 조직병리학분야 이론 $60.5 \%$, 실습 $39.5 \%$; 임상생리학분야 $31.5 \%$, 실습 $68.5 \%$ 로 나타났다. 임상화학분야, 혈액학분야, 미생물분야는 이론과 실습이 거의 비슷한 비율을 나타냈지만 조직병리학분야의 경우는 이론이 높 게, 임상생리학분야는 실습이 이론에 비해 2.1 배 높게 나타났다 (Table 3).

\section{4) 주 교과 분야별 구성 교과목수}

10 개교 이상이 교육과정으로 채택한 분야별 주교과목 구성 을 보면 전공기초분야 9과목으로 임상병리학 개론, 의학용어, 인체해부학, 인체생리학, 면역학, 일반생물학, 유기화학 및 일 반화학, 분자생물학, 생화학 등으로 구성되어 있으며 기타 과목 으로 물리학, 세포학 및 세포생리학, 병리학특론으로 구성되어 있다. 조직병리학분야는 4과목으로 병리학, 조직학, 조직검사 학, 진단세포학으로 구성되어 있으며, 그 밖에 분자병리학이 있 다. 혈액학분야는 2과목으로 혈액학과 수혈학으로 구성되어 있 다. 임상화학분야는 3과목으로 임상화학, 요화학 및 체액검사 학, 핵의학검사학 또는 동위원소검사학으로 구성되어 있으며, 그 밖에 정도관리학이 있다. 미생물학분야는 5 과목으로 임상미 생물학 또는 세균학, 진균학, 바이러스학, 임상기생충학, 면역 혈청학 등으로 구성되어 있으며, 그 밖에 항생물질학이 있다. 임 상생리학분야는 5과목으로 임상생리학, 신경기능검사학, 순환 기능검사학, 호흡기능검사학, 초음파검사학로 구성되어 있으 며, 그 밖에 기타 생리기능검사학도 있다.

\section{5) 교육과정 편성 비율}

교육과정 편성 평균학점은 전공기초 26 학점으로 $21 \%$ 를 차 지하였으며, 전공 76.7 학점으로 $61 \%$, 교양은 13.9 학점으로 $11 \%$ 를 기타 과목으로는 9학점으로 $7 \%$ 를 차지하였다. 그리고 총 125.6학점으로 구성되어 있다(Table 4).

\section{6) 중요과목 학기별 분포}

중요교과목 학기별 분포는 전공 기초교과목은 대부분 1 학년 1 학기에서 2학기에 걸쳐 분포하고 있으나 면역학의 경우 2학년 1 학기, 유전학을 포함한 분자생물학은 2학년 1학기 2학기에 분 포하고 있는 것으로 분석되었다. 조직병리학분야의 경우 조직 검사학은 2학년 1학기, 조직학실습은 2학년 2학기에 주로 분포 하고 있으며, 진단세포학은 2학년 2학기에서 3학년 1학기에 분 포하고 있는 것으로 분석되었다. 혈액학분야는 혈액학은 1 학년 2학기와 2학년 1학기에 분포하고 혈액학 실습은 2학년 1학기 와 2학기에, 수혈학 및 실습은 2학년 1학기와 2학기에 분포하는 것으로 분석되었다. 임상화학분야는 1학년 2학기부터 2학년 2 학기까지, 임상화학 실습은 2학년 1학기부터 3학년 1학기까지 분포하고 있으며, 요화학 및 체액검사학 실습은 1학년 1학기부 터 2학년 1학기까지, 그리고 핵의학은 3학년 1학기와 2학기에 분포하고 있었다. 미생물학분야는 임상미생물학은 2학년 1학 기와 2학기에, 바이러스학 및 진균학은 2학년 2학기, 3학년 1학 기에 분포하고 있으며, 임상기생충학은 1학년 2학기에서 2학년 1 학기, 면역혈청학 및 실험은 2학년 1학기, 2학기에 분포하고 특이하게도 감염관리학은 3학년 2학기에 주로 개설되어 있지 만 전 학년에 걸쳐 분포하는 특징 있었다. 분자유전학 및 세포유 전학은 2학년에 주로 분포하고 있다. 임상생리학분야는 2학년 1학기부터 3학년 1학기까지 분포하고 있으며, 공중보건학과 보 건의료법규는 3학년에 분포하고 있다. 임상실습의 경우는 3학 년에 개설되어 분포하고 있다.

\section{4 년제 25 개교 교육과정 분석}

4년제 대학의 교육과정을 전공기초분야, 검사의학 분야(핵 의학 포함), 조직병리학분야, 임상생리학분야, 병원현장실습, 국가고시 필수과목, 기타과목으로 나누어 분석하였다. 우리나 라의 4년제 대학 총 25 개교를 모두 분석하였고 필수교양 또는 교양선택 과목이지만 전공기초과목으로 분류하는 경우와 두과

Table 3. Lecture and laboratory ratio of major subjects (\%)

\begin{tabular}{|c|c|c|c|c|c|c|c|c|c|}
\hline \multicolumn{2}{|c|}{ Clinical chemistry } & \multicolumn{2}{|c|}{ Hematology } & \multicolumn{2}{|c|}{ Microbiology } & \multicolumn{2}{|c|}{ Histopathology } & \multicolumn{2}{|c|}{ Clinical physiology } \\
\hline Lec & Lab & Lec & Lab & Lec & Lab & Lec & $\mathrm{Lab}$ & Lec & $\mathrm{Lab}$ \\
\hline 53 & 47 & 50.1 & 49.9 & 54.6 & 45.4 & 60.5 & 39.5 & 31.5 & 68.5 \\
\hline
\end{tabular}

Abbreviations: Lec, lecture; Lab, laboratory.

Table 4. Average credits and percents of 3-year universities

\begin{tabular}{cccccc}
\hline Course & Basic subjects & Major subjects & Liberal arts subject & Other & Total \\
\hline Credits $(\%)$ & $26(21)$ & $76.7(61)$ & $13.9(11)$ & $9(7)$ & $125.6(100)$ \\
\hline
\end{tabular}


목이 하나의 과목으로 합쳐진 경우도 있었다.

\section{1) 대학 학점구성 및 비율}

분석결과 4년제 대학 과목별 평균학점으로 전공기초 34.9학 점(25\%), 조직병리학 9.4 학점(7\%), 혈액학 10.2 학점(7\%), 임상 화학 28.5학점(21\%), 미생물학 19.6학점(14\%), 분자진단학 5.9학점(4\%), 임상생리학 18.3 학점(13\%), 공중보건학 2.5학점 (2\%), 보건의료법규 2.3 학점(2\%), 병원현장실습 7.4 학점(5\%) 으로 개설되어 있었다. 전공기초에는 임상병리학 개론, 의학용 어/임상영어, 인체해부학, 인체생리학, 생화학, 조직학, 생물리 화학/일반물리학, 세포생물학, 병리학, 면역학, 일반생물학/생 명과학, 유기화학/화학, 세포학/세포생리학, 분자생물학, 약리 학/독성학, 생명공학/바이오의학, 단백체학, 임상병리학 특론/ 기초실험으로 구분하였다. 검사의학은 크게 혈액학, 화학, 미생 물학, 분자진단학으로 구분하고 혈액학에는 혈액학/유세포측 정, 수혈학; 화학에는 임상화학, 면역화학, 요화학/체액검사학, 핵의학/동위원소검사학, 생체시료분석학/미세질량분석학, 기 기분석학, 정도관리학; 미생물학은 임상미생물학, 세균학, 진균 학, 바이러스학, 임상기생충학, 감염병학/역학개론, 감염관리 학, 미생물혈청학; 분자진단학은 분자유전학, 세포유전학, 조직 적합성검사학으로 구분하였다. 조직병리학에는 조직학/조직 검사학, 진단세포학, 분자병리학으로 구분하였다. 임상생리학 은 순환기능검사학, 호흡기능검사학, 신경기능검사학, 초음파 검사학, 기타생리기능검사학, 체외순환학으로 구분하였다 (Table 5).

\section{3. 임상실습현황 조사 분석}

도출된 임상실습의 문제점은 임상실습의 시행시기, 임상실 습성적의 교육과정반영에 관한 사항, 임상실습교육 기관, 임상 실습교육의 내용 및 운영에 관한 사항 등이 있었다. 대학의 교수 는 79명이 응답하였고, 산업체의 임상병리사는 1358 명이 응답 하여 분석하였다.

\section{1) 임상실습조사 분석}

(1) 임상실습 시행 시기에 대한 조사

각 대학에서 임상실습을 시행하는 시기에 대한 현황조사를
분석함으로써 임상현장의 교육에 대한 수요-공급불일치에 대 한 해결방안을 모색하고, 현장교육의 질을 제고하기 위한 기초 자료로 활용하고자 하였다. 따라서 현행 각 대학에서 임상실습 을 실시하는 시기에 대하여 1학기 중, 하계방학, 2 학기 중, 동계 방학으로 구분하여 각 대학의 교수를 대상으로 실습현황에 대 한 설문을 실시하고, 동시에 임상현장에서 생각하는 적절한 시 기를 분석하였다. 대부분의 대학에서 임상실습 시행을 매년 2회 이상에 걸쳐서 인원을 분산해서 실시하기 때문에 현황분석에 대한 설문조사는 시기별 중복선택이 가능하도록 하였다. 그 결 과 대학에서는 동계방학에 실시하는 경우가 $87 \%$, 하계방학 기 간이 $49 \%$ 로 동계방학에 실시하는 경우가 절대적으로 우세하게 나타났다. 1 학기 기간 중은 $5 \%, 2$ 학기 기간 중 실시하는 대학은 $1 \%$ 로 거의 없는 것으로 조사되었다. 임상현장의 수요분석에 대 한 설문조사에서는 동계방학 중 실시가 적합하다는 의견이 $50 \%$ 로 가장 높았고, 하계방학 중이라는 의견도 $32 \%$ 로 조사되 었다. 이는 현행 대학의 현황조사와 시기적으로 어느 정도 일치 하는 소견을 보였다. 하지만 2학기 중에 실시하는 것이 최적의 시기라고 응답한 경우가 $34 \%, 1$ 학기 중이라는 의견도 $14 \%$ 를 차지하였다.

(2) 임상실습성적의 교육과정 반영 학점에 대한 조사

임상실습교육 종료 후, 실습생의 개인별 실습성적이 각 소속 대학으로 발송된다. 각 대학 교육과정의 전체 이수학점에서 임 상실습성적을 반영하고 있는 학점현황을 대학을 대상으로 조사 하고, 동시에 적절한 학점반영에 대한 임상현장 전문가의 의견 을 비교·분석하였다. 전공교과 한 과목의 학점이 2 3학점임을 감안하여 최소인정학점을 3학점 이하로 두고, 3학점 간격으로 적절한 학점반영에 대한 설문문항 답가지를 설정하였고, 최대 반영학점은 한 학기 인정학점에 해당하는 16학점이상으로 제 시하였다. 그 결과 대학의 경우 4 6학점을 반영하고 있는 비율 이 49\%로 가장 높게 나타났고, 7 9학점, 10 12학점, 3학점 이하로 반영하는 순으로 조사되었다. 13학점이상을 반영하는 대학은 $2 \%$ 이내로 매우 낮은 분포를 보였다. 임상현장에서 생각 하는 적절한 반영학점은 10 12학점이 33\%로 가장 높게 나타 났고, 그 다음으로 4 6학점, 7 9학점, 3학점 이하, 16학점 이 상, 13 15학점 순으로 조사되었다. 현행 대부분의 대학에서 반영하고 있는 임상실습학점과 임상에서 적절하다고 제시한 반

Table 5. Average credits and percents of 4-year universities

\begin{tabular}{cccccccccccc}
\hline Field & $\begin{array}{c}\text { Basic } \\
\text { subjects }\end{array}$ & $\begin{array}{c}\text { Histo- } \\
\text { pathology }\end{array}$ & Hematology & $\begin{array}{c}\text { Clinical } \\
\text { chemistry }\end{array}$ & $\begin{array}{c}\text { Micro- } \\
\text { biology }\end{array}$ & $\begin{array}{c}\text { Molecular } \\
\text { diagnosis }\end{array}$ & $\begin{array}{c}\text { Clinical } \\
\text { physiology }\end{array}$ & $\begin{array}{c}\text { Public } \\
\text { health }\end{array}$ & $\begin{array}{c}\text { Health and } \\
\text { medical law }\end{array}$ & $\begin{array}{c}\text { Clinical } \\
\text { practicum }\end{array}$ & Total \\
\hline $\begin{array}{c}\text { Credits } \\
(\%)\end{array}$ & 34.9 & 9.4 & 10.2 & 28.5 & 19.6 & 5.9 & 18.3 & 2.5 & 2.3 & 7.4 & 139 \\
$(25)$ & $(7)$ & $(7)$ & $(21)$ & $(14)$ & $(4)$ & $(13)$ & $(2)$ & $(2)$ & $(5)$ & $(100)$ \\
\hline
\end{tabular}


영학점 간에는 4 8학점 정도의 차이가 있는 것으로 분석되었 고, 현행 반영하고 있는 학점에 대해 적절하다는 의견도 $23 \%$ 에 해당하는 것으로 나타났다. 또한 13학점 이상 반영해야 한다는 임상현장 전문가들의 의견이 $12 \%$ 인 반면, 현행 대학에서는 $2 \%$ 정도에 불과한 것으로 분석되었다(Table 6).

(3) 임상실습성적의 교육과정 반영 방법에 대한 조사

각 대학에서 임상실습성적을 반영하는 방법은 다소 차이가 있다. '임상실습 교과목을 별도로 개설하여 임상실습성적 전체 를 반영하는 경우'와 '임상실습 교과목을 개설하지 않고, 일반 교과목에 임상실습성적의 일부를 반영하는 경우'가 대표적인 사례이다. 다양한 사례는 아니지만 임상실습성적의 평가표준 화 관점에서 볼 때 가장 적절한 평가방법에 대한 결론을 도출하 기 위한 기초자료를 확보하기 위하여 설문을 실시하였다. 그 결 과 현행 많은 대학에서 시행하고 있는 평가반영방법과 임상현 장의 전문가가 제시한 의견이 각 $84 \%, 74 \%$ 정도로 동일하게 높 은 비율로 일치하는 결과를 보였다. 하지만, 임상현장 의견의 경 우 일반교과목에 임상실습성적의 일부를 반영하는 것이 적절하 다는 의견도 $24 \%$ 로 비교적 높게 조사되었다. 기타 대학의 경우 는 임상실습 교과목을 별도로 개설하여 실습성적과 대학에서의 성적(중간, 기말, 지필고사)을 반영하는 경우도 있는 것으로 나 타났다. 설문문항에서 제시한 대표사례 이외에도 다양한 기타 평가방법에 대한 의견을 수렴하여 최적의 표준화된 평가방법을 선택해야 할 것으로 판단된다.

기타 임상현장의 의견으로 임상현장의 급속한 발전으로 인 하여 임상실습교육을 해도 취업 후 어차피 새롭게 배워야하는 한계를 언급하는 의견도 있었고, 임상실습의 평가도 중요하지 만 실습교육 자체가 단순한 잡일이 아닌 보다 구체적이고 체계 적인 교육을 시행해야 한다는 의견도 있었다. 또한 동일한 연장 선상에서 표준화된 임상실습관련지정기관을 설립하여 인증 후 시행 및 평가의 단계를 밟아야 한다는 기타 의견도 있었다. 일부 에서는 임상실습을 견학위주의 단기실습으로 전환하고 대학의 실습만을 강화하자는 의견도 있었다.

Table 6 . The results of the survey on the credits of the clinical practicum

\begin{tabular}{lcc}
\hline Credits & Professors (N/\%) & Medical technologists (N/\%) \\
\hline$\leq 3$ & $8 / 10$ & $141 / 11$ \\
$4 \sim 6$ & $39 / 50$ & $324 / 24$ \\
$7 \sim 9$ & $17 / 22$ & $272 / 19$ \\
$10 \sim 12$ & $13 / 16$ & $457 / 33$ \\
$13 \sim 15$ & $1 / 1$ & $53 / 4$ \\
$\geq 16$ & $1 / 1$ & $111 / 8$ \\
\hline
\end{tabular}

(4) 임상실습성적의 교육과정 반영 시기에 대한 조사

각 대학에서 임상실습성적을 반영하는 시기에도 다소 차이 가 있다. '학기 중에 임상실습을 시행하여 해당학기 성적에 반영 하는 경우’와 ‘방학기간에 임상실습을 시행하여 계절학기 성적 에 반영하는 경우', '방학기간에 임상실습을 시행하여 다음 학 기 성적에 반영하는 경우 '등이 대표적인 사례이다. 반영시기 또 한 다양한 사례는 아니지만 임상실습성적의 평가표준화 관점에 서 볼 때 가장 적절한 평가방법에 대한 결론을 도출하기 위한 기 초자료를 확보하기 위하여 설문을 실시하였다. 그 결과 대학의 현황과 임상전문가의 의견에 다소 차이가 있었다. 현행 $81 \%$ 에 해당하는 대학에서 '방학기간에 임상실습을 시행하여 다음 학 기 성적에 반영'하고 있는데 반해 임상현장에서는 ‘학기 중에 임 상실습을 시행하여 해당학기 성적에 반영'하는 것이 좀 더 적절 하다고 하였다. 이런 방식으로 반영하는 대학은 $6 \%$ 인 것으로 나 타났다. 또한 '방학기간에 임상실습을 시행하여 계절학기 성적 에 반영'하는 것에 대한 대학의 현황과 임상의 의견은 $11 ~ 12 \%$ 의 낮은 수준에서 비슷한 분포로 분석되었다. 그 외 어느 대학의 경우는 일괄적으로 4 학년 2학기에 성적을 반영하는 경우도 있 었다. 이는 임상실습의 기간과 시기에 따라 달라질 수 있는 경우 로서 임상실습의 평가에 대한 표준화를 위해서는 다양한 관점 에서 변수를 고려해야함을 시사하는 결과로 판단된다. 임상현 장의 기타 의견으로 임상실습의 필요성에 의문을 제기하거나, 장기간의 임상실습이 필요하다는 의견도 있었다.

(5) 임상실습성적의 평가방법에 대한 조사

대학의 성적평가 방법은 절대평가, 상대평가 및 Pass/ Non-pass (fail) 등이 있다. 따라서 각 대학에서 임상실습성적 을 반영하는 평가방법에도 다소 차이가 있다. "임상실습성적(이 반영되는) 교과목은 절대평가로 $\mathrm{A} \sim \mathrm{F}$ 학점으로 세분화 평가하 는 경우'와 '임상실습성적(이 반영되는) 교과목은 상대평가로 A $\mathrm{F}$ 학점으로 세분화 평가하는 경우, '임상실습성적(이 반영되는) 교과목은 Pass/Non-pass로 평가하는 경우'등이 대표적인 사 례이다. 임상실습성적의 가장 적절한 평가방법에 대한 결론을 도출하기 위한 기초자료를 확보하기 위하여 설문을 실시한 결 과 현행 대학의 평가현황과 임상현장 전문가의 의견이 동일하 게 나타났다. 두 그룹 모두에서 가장 적절한 평가방법은 '임상실 습성적(이 반영되는) 교과목은 절대평가로 $\mathrm{A} \sim \mathrm{F}$ 학점으로 세분 화 평가'하는 것으로 현행 대학에서 $62 \%$ 정도가 실시하는 방법 으로 조사되었고, 임상현장의 의견도 $44 \%$ 로 가장 높은 방법으 로 판단했다. 그 다음으로는 '임상실습성적(이 반영되는) 교과 목은 Pass/Non-pass로 평가' 하는 것으로 21\%의 대학에서 적 용하고 있는 것으로 조사되었고, 임상현장의 의견은 $36 \%$ 로 적 
절하다는 응답을 했다. '임상실습성적(이 반영되는) 교과목은 상대평가로 $\mathrm{A} \sim \mathrm{F}$ 학점으로 세분화 평가’하는 대학은 $15 \%$ 로 가 장 낮은 수치로 조사되었으나 12 개 대학에서 이와 같이 평가하 고 있는 것으로 나타났고, 임상현장에서도 $18 \%$ 에서 이 평가방 법이 적절하다고 응답하였다.

\section{2) 임상실습의 문제점과 개선점}

(1) 임상실습교육 기관의 적절성 조사

임상실습교육 종료 후, 피교육자인 재학생과의 피드백을 수 행하는 각 대학의 입장에서 임상실습교육에 적합한 기관에 대 한 설문조사를 분석하고자 하였다. 이를 통해 현장교육의 다면 화, 재학생 현장교육 선택권확대, 업무영역 세분화 및 확대에 따 른 현장교육내용 대응, 취업현황과 연계한 시대의 추세에 따른 실제적 교육 방안 등의 기초자료로 활용하고자 하였다. 임상실 습 순회 지도를 통하여 다양한 임상실습기관과 교류하고 있는 각 대학의 교수를 대상으로 설문을 실시하고, 임상실습기관의 공유 및 최적의 임상실습교육에 대한 의견을 수렴하는 차원에 서 중복선택이 가능하도록 하였다. 그 결과 종합병원이 $98 \%$ 로 압도적으로 높은 비율을 보였고, 준 종합병원 53\%, 검사센터 $39 \%$, 건강관리협회 $18 \%$, 의생명연구소 $11 \%$, 혈액원과 보건소 는 각 $7 \%$ 로 조사되었다.

(2) 임상실습교육 분야의 적절성 조사

현행 임상실습교육은 다양한 의료기관 및 취업·전공 대상기 관에서 대부분 8 주의 기간으로 운영하고 있으나, 각 실습기관마 다 실습교육 분야 및 분야별 일정을 그 기관의 형편에 맞도록 운 영하고 있다. 임상실습교육의 표준화와 임상병리사의 업무영 역 및 세분화되고 있는 시대의 요구에 부응하는 현장교육을 위 한 필수임상실습교육에 대한 최적의 교육시간을 파악하기 위하 여 임상실습교육 분야의 적절성을 조사하고자 하였다. 임상실 습교육 분야는 검사의학 분야, 조직병리학분야, 핵의학분야, 임 상생리학분야로 설정하고, 그 외기타 교육이 필요한 분야에 대 한 의견을 수렴하고자하였다. 임상실습교육의 적절성에 대한 각 분야별 \%비율을 분석하기 위하여 중복선택이 가능하도록 설 정하였다. 그 결과 교수그룹과 임상현장그룹의 분야별 전반적 인 교육시간에 대한 비중은 동일하였다. 하지만, 중복선택을 허 용했음에도 동일한 분야에서도 두 그룹간의 차이가 있었고, $100 \%$ 에 가깝게 응답하지 않은 분야도 나타났다. 교육시간 비중 이 가장 높아야한다고 응답한 분야는 검사의학 분야로 조사되 었고, 그 다음으로 임상생리학분야 $\rightarrow$ 조직병리학분야 $\rightarrow$ 핵의 학분야 $\rightarrow$ 기타분야 분석되었다. 또한 교수그룹에 비해 임상현 장그룹은 모든 분야에서 13\% 22\%정도 낮은 수치를 보였다.
특히 교수그룹에서는 진단검사의학, 임상생리학 분야가 $90 \%$ 이 상차지하였고, 거의 동일한 수준으로 조사되었다. 그 외 기타분 야에 대한 의견으로는 교수그룹의 경우 건강검진, 세포배양, 조 직배양 등에 관한 교육이 이루어져야 한다는 의견이 있었다. 임 상현장의 경우는 학제단일화로 모든 학제가 4년제로 바뀌어 진 다면 임상실습교육기간을 1년으로 하여 심도 있는 현장교육이 필요하다는 의견이 있었다. 또, 검사업무를 진행하는 전공분야 에만 국한되지 않고, 보험심사부서 등과 같이 범위를 넓혀 전공 과 교양을 함께 체험할 수 있는 교육의 필요성도 언급하였다. 청 력검사(어지럼증), 검진센터(실무), 임상생리학분야의 세분화 된 교육, 채혈강화, 안과검사, 동맥경화, 수면다원검사 등에 대 한 의견이 주를 이루었다. 특히 임상생리학 분야의 세분화된 교 육이 이루어져야한다는 의견이 주로 기타의견으로 조사되었다.

(3) 임상실습교육 분야별 교육시간 적절성 조사

임상실습교육의 주요 분야인 검사의학, 조직병리학, 핵의학, 임상생리학에 대하여 분야별 실습강도 및 실무교육의 범위에 대한 필요성에 대하여 분석하고자 하였다. 이를 통해 시대의 요 구 변화 및 의료 환경변화에 따라 세분화, 전문화되는 실무환경 에 대처하고, 대학교육의 방향과 깊이를 설정하는 기초자료로 활용하고자 하였다. 또한 주요 전공분야에 대한 실무교육의 필 요성에 대해 대학과 임상현장에서 인식하는 차이를 분석하여, 대학교육의 방향과 실무현장의 실제에 차이가 있는지도 함께 조사하고자 하였다.

(1) 교수: 검사의학 분야의 임상실습 교육비율은 전체에서 $40 \%$ 정도 비중을 두는 것이 바람직하다는 의견이 $37 \%$ 로 가장 높았고, 전체에서 $50 \% \rightarrow 30 \% \rightarrow 60 \% \rightarrow 20 \% \rightarrow 10 \%$ 또는 $90 \%$ 의 비중을 두는 것이 적절하다는 의견 순으로 나타났다. 임상생 리학분야는 전체에서 $20 \%$ 정도 비중을 두는 것이 적절하다는 의견이 $50 \%$ 로 조사되었고, 그 다음으로는 $30 \% \rightarrow 10 \% \rightarrow 50 \%$ 로 비중을 두는 것이 적절하다는 의견 순으로 나타났다. 조직병 리학 분야도 $20 \%$ 정도 비중이 가장 적절한 것으로 $55 \%$ 에서 응 답하였고, 그 다음으로 $30 \% \rightarrow 10 \% \rightarrow 50 \%$ 의 순으로 나타나 임 상생리학의 교육비율과 동일한 빈도로 응답하였다. 핵의학분 야는 임상실습이 불필요하다는 의견이 $59 \%$ 로 가장 높은 비율 을 보였고, 그 다음은 $10 \% \rightarrow 20 \% \rightarrow 30 \%$ 의 순으로 조사되었다. 그 외 주요전공분야 이외의 기타 분야에 대해서도 $10 \%$ 정도는 임상실습 교육을 실시해야한다는 의견도 $30 \%$ 를 차지하였다.

(2) 임상현장: 검사의학 분야의 임상실습 교육비율은 전체에 서 30\%정도 비중을 두는 것이 바람직하다는 의견이 $25 \%$ 로 가 장 높았고, 전체에서 $50 \% \rightarrow 40 \% \rightarrow 20 \% \rightarrow 60 \% \rightarrow 70 \%$ 의 비중 을 두는 것이 적절하다는 의견 순으로 나타났다. 임상생리학분 
야는 전체에서 $20 \%$ 정도 비중을 두는 것이 적절하다는 의견이 $47 \%$ 로 조사되었고, 그 다음으로는 $30 \% \rightarrow 10 \% \rightarrow 40 \% \rightarrow 50 \%$ 로 비중을 두는 것이 적절하다는 의견 순으로 나타났다. 조직병 리학 분야도 $20 \%$ 정도 비중이 가장 적절한 것으로 $50 \%$ 에서 응 답하였고, 그 다음으로 $30 \% \rightarrow 10 \% \rightarrow 40 \% \rightarrow 50 \%$ 의 순으로 나 타나 임상생리학의 교육비율과 동일한 빈도로 응답하였다. 핵 의학분야는 $10 \%$ 정도 비중이 가장 적절한 것으로 $53 \%$ 에서 응 답하였고, 그 다음은 $20 \% \rightarrow 0 \% \rightarrow 30 \%$ 의 순으로 조사되었다. 그 외 주요전공분야 이외의 기타 분야에 대해서도 $10 \%$ 정도는 임상실습 교육을 실시해야한다는 의견도 $32 \%$ 를 차지하였다.

(4) 임상실습교육 운영방식의 적절성 조사

임상실습교육을 '시행'과 ‘평가' 두 가지 관점에서 보았을 때, ‘시행'의 가장 핵심은 교육스케줄이라고 할 수 있다. 교육스케 줄은 실습교육의 분야 및 분야별 실습시간을 모두 포함하고 있 으므로 임상실습의 표준화를 위해서는 가장 상위개념으로 표현 할 수 있다. 임상실습교육을 시행하는 각 기관의 운영방식은 각 기관의 물리적 여건에서 자유로울 수는 없으나, 운영방식을 크 게 세 가지 방법으로 제시하여 적절한 운영방식에 대한 의견을 수렴하여 기초자료를 확보하고자 하였다. 즉 '실습기관별 교육 스케줄에 따라 참여 실습생의 일괄교육 하는 방식'과 '모든 실습 기관이 동일한 교육스케줄에 따라 참여 실습생의 일괄교육 하 는 방식', '참여 실습생이 교육 분야를 선택하여 집중교육 하는 방식'으로 구분하였고, 기타 방식에 대한 의견도 수렴하고자 하 였다. 임상실습교육 운영방식의 가장 적절한 방법에 대한 결론 을 도출하기 위한 설문결과 '실습기관별 교육스케줄에 따라 참 여 실습생의 일괄교육 하는 방식'이 두 그룹 모두에서 가장 높게 나타났다. 그 다음으로는 '모든 실습기관이 동일한 교육스케줄 에 따라참여 실습생의 일괄교육 하는 방식'이 교수와 임상현장 에서 각 $39 \%, 35 \%$ 로 조사되었다. '참여 실습생이 교육 분야를 선택하여 집중교육 하는 방식'은 가장 낮은 응답률을 보였는데, 임상현장의 경우는 $17 \%$ 정도로 교수그룹 보다는 6 배정도 높게 조사되었다. 세 가지 방식에 대한 적절성에 대한 분포는 대학, 임상현장 두 그룹 모두에서 동일한 순서로 나타났다. 그 외 별도 의 임상실습기관을 운영하여 일관된 교육을 실시하자는 의견과 전문분야에 대한 집중적인 교육이 필요하다는 기타 의견이 있 었다.

(5) 임상실습교육 평가방식에 대한 적절성 조사

임상실습성적의 평가방법과는 별개로 어떠한 절차와 방식으 로 성적을 산출하는 것이 적절한지에 대한 설문을 실시하였다. 이것은 실습생 개인별 점수가 각 대학으로 발송되기 전에 임상 실습현장에서 실습성적을 산출하는 단계에서 평가방식에 대한
표준화 방안을 얻고자 하였다. 평가방식에 대하여 세 가지 기본 안을 제시하고, 그 이외의 기타의견을 수렴하는 방식으로 설문 을 실시하였다. 즉 '각 실습교육기관의 평가기준에 따라 임상실 습담당자가 평가하여 대학으로 통보하는 방식'과 ‘표준화된 평 가기준에 따라 각 실습교육기관의 임상실습담당자가 평가하여 대학으로 통보하는 방식', '각 대학의 임상실습평가 담당교수가 실습기관을 방문하여 평가하는 방식'에 대하여 설문을 실시하 였다. 그 결과 대학과 임상현장 두 그룹 간에 적절한 방식의 순위 와 빈도가 모두 유사하게 분석되었다. 가장 적절한 방식으로 조 사된 것은 “표준화된 평가기준에 따라 각 실습교육기관의 임상 실습담당자가 평가하여 대학으로 통보'하는 것으로 조사되었 고, 두 그룹 모두 63\%이상 응답률을 보였다. 그 다음으로 26\% $29 \%$ 에서 '각 실습교육기관의 평가기준에 따라 임상실습담당 자가 평가하여 대학으로 통보' 하는 현행의 방식이 적절하다고 응답하였다. 반면 '각 대학의 임상실습평가 담당교수가 실습기 관을 방문하여 평가'하는 방식은 두 그룹 모두에서 3\% 5\%수 준으로 적절성이 낮은 것으로 조사되었다. 그 외 표준화된 평가 기준에 따라 임상실습현장의 점수와 대학교수의 점수를 병행하 여 평가하자는 절충의견과 대학자체의 평가 비율을 정하여 평 가하는 방식, 실습기관이 전적으로 평가하여 통보 후, 대학의 재 량으로 성적을 산출하는 방식 등이 기타 의견으로 조사되었다.

(6) 임상실습성적의 교육과정 반영 학점에 대한 적절성 조사

임상실습성적을 반영하는 적절한 학점수를 도출하기 위하여 현행 각 대학에서 적용하고 있는 학점, 교수의 의견, 임상전문가 의 의견 등 세 부분의 의견을 종합하여 분석하였다. 그 결과 대학 에서 현행 실시하고 있는 현황과 교수그룹의 의견은 정도의 차 이는 있었지만, 빈도분포에서 동일한 결과를 보였다.

(7) 임상실습성적 평가방법의 적절성 조사

임상실습성적의 적절한 성적처리 방법을 도출하기 위하여 현행 각 대학에서 적용하고 있는 평가방법, 교수의 의견, 임상전 문가의 의견 등 세 부분의 의견을 종합하여 분석하였다. 그 결과 대학에서 현행 실시하고 있는 현황과 교수그룹의 의견은 빈도 분포에서 동일한 순서를 보였지만, '임상실습성적(이 반영되 는) 교과목은 Pass/Non-pass로 평가' 하는 방식이 설문조사에 서는 19\% 더 높게 나타났다. 이러한 평가방법은 임상현장의 설 문분석 결과와 유사한 경향으로 조사되었다. 하지만, '임상실습 성적(이 반영되는) 교과목은 절대평가로 $\mathrm{A} \sim \mathrm{F}$ 학점으로 세분화 평가'하는 방식이 세 부분 모두에서 가장 높은 비율로 나타났다. 


\section{4. 해외교육과정 및 실습조사 분석}

1) 미국의 교육과정

(1) 미국 Medical Laboratory Scientist (Medical Technologist, Clinical Laboratory Scientist) 교육과정 미국 Medical Laboratory Scientist (MLS), Medical Technologist (MT), Clinical Laboratory Scientist (CLS) 프로그램은 American Society of Clinical Pathologist (ASCP)의 자격증 취득 요건과 NAACLS (National Accrediting Agency for Clinical Laboratory Science NAACLS)의 Unique Standards Medical Laboratory Scientist (MLS)을 기본으로 하여 각 교육 기관에서 교육과정을 설계하고 교육프로그램으로서 인증을 받 는 형식을 가지고 있다[6, 7]. 현재 학사학위 과정은 4년제 대학 교와 대학병원이나 인증 받은 병원에서 운영하는 프로그램 총 234 개의 프로그램이 있다. 미국은 4년제 학사의 경우 일반적으 로 120학점 이상을 취득하고 이론과목 이외에 실험 및 임상실 습기간을 포함하고 있다. 대부분의 4년간의 교육과정에서 요구 되는 내용이 포함되도록 설계되어 있으며 pre- professional 단 계와 professional 단계로 나누어 교육을 시행하고 있고 1년 혹 은 2년간 실험실 경험(학교실습 및 임상실습)을 할 수 있는 기간 을 수행하도록 되어 있다. Pre-professional 단계는 생물학(생 리학), 화학(일반화학 혹은 유기화학), 수학, 통계학, 기본교양 등을 이수하는 단계이고, professional 단계는 좀 더 MLS에 집 중된 시기로 생화학, 미생물학, 임상화학, 임상미생물학, 면역 학, 혈액학, 수혈학에 대한 이론과 실습과목, 그리고 경영관리, 의사소통, 교육학, 연구 등 관리자로서 기능에 대한 과목을 이수 하는 단계이다. 마지막으로 4학년 기간 동안 실제적인 임상경험 을 하는 단계로 이루어져 있다. 대부분의 학교가 임상실습은 한 학기 정도의 기간으로 구성되어 있다[8-13].

(2) 미국 Medical Laboratory Technician 교육과정

미국 Medical Laboratory Technician (MLT) 프로그램은 $\mathrm{ASCP}$ 자격증 취득 요건과 NAACLS을 기본으로 하여 각 교육기 관에서 교육과정을 설계하고 교육프로그램으로서 인증을 받는 형식을 가지고 있다. 현재 전문학사학위 과정은 2년제 대학과 인증 받은 병원에서 운영하는 프로그램 총 237 개의 프로그램이 있다. 미국은 2년제 학사의 경우 일반적으로 60 학점 이상을 취 득하고 이론과목 이외에 실험 및 임상실습기간을 포함하고 있 다. 대부분의 2년간의 교육과정에서 설명되는 내용이 포함되도 록 설계되어 교육을 시행하고 있고 1년 실험실 경험(학교실습 및 임상실습)을 할 수 있는 기간을 수행하도록 되어 있다. 이수 과목으로는 화학(일반화학), 기본교양(심리학, 윤리학), 영어작
문, 의사소통 등을 이수하는 단계와 좀 더 MLT에 집중된 과목으 로 세포분자생물학, 기생충/진균학, 미생물학, 혈액학, 임상화 학, 소변 및 체액분석학, 임상미생물학, 면역학에 대한 이론과 실습과목, 임상실습과목을 이수하는 단계이다. 대부분의 학교 가 임상실습은 한 학기 정도의 기간으로 구성되어 있다 $[6,7]$.

\section{2) 캐나다의 교육과정}

캐나다 Medical Laboratory Technologist (MLT) 프로그램 은 Canadian Society for Medical Laboratory Science (CSMLS)의 자격증 취득 요건과 CMA (Canadian Medical Association)의 Competency Profile General Medical Laboratory Technologist를 기본으로 하여 각 교육기관에서 교육과정을 설계하고 교육프로그램으로서 인증을 받는 형식을 가지고 있다. 현재 전문학사학위 과정은 총 18 개의 프로그램이 2017년 현재 인증되어 있고, 이후 학사학위를 받아 경력을 발전 할 수 있는 체계를 가지고 있다. 학사학위 프로그램은 2개의 대 학교에서 운영되고 있다. 대부분의 2년 반의 교육과정으로 프로 그램이 구성되어 있으며, 이수과목은 화학, 임상병리학 개론, 심 리학, 윤리학, 의사소통 등의 과목과 좀 더 MLT에 집중된 과목 으로 임상화학, 미생물학, 임상미생물학, 면역학, 혈액학, 수혈 학, 분자진단기법에 대한 이론과 실습과목, 임상실습에 대한 과 목으로 구성된다. 캐나다의 임상실습과정은 대개 1 년의 기간을 시행하고 있다[14-16].

\section{3) 호주의 교육과정}

호주의 Medical Laboratory Scientist (MLS)의 경우 3년 또 는 4년제의 대학교에서 임상병리학과(medical laboratory science) 전공하고 학사학위를 받아야 하고, 모든 교육프로그 램은 Australian Institute of Medical Scientists (AIMS)에서 인 증을 받아야한다. 현재 학사학위 과정은 총 11 개의 프로그램이 2017년 현재 인증되어 있다. 대부분의 4년제 교육과정에서 요 구되는 내용이 포함되도록 설계되어 있으며, 이수과목은 해부 생리학, 임상병리학 개론, 유기화학, 미생물학, 혈액학, 생화학, 면역학, 조직학 등의 과목과 좀 더 MS에 집중된 과목으로 임상 미생물학, 생명공학, 임상생화학, 세포병리학, 수혈의학, 생물 학적 연구 디자인, 임상실습에 대한 과목으로 구성된다. 호주의 임상실습과정은 대개 1년의 기간을 시행하고 있다[17-19].

\section{고 찰}

3년제 교육과정은 학점의 비율로 보면 임상병리사국가시험 
의 문항수에 따라서 학점이 편성되어 있음을 알 수 있었다. 또한 이론과 실습의 경우는 과목별 특성에 따라 이론과 실습이 1:1비 율로 나타났으나 조직병리학은 경우는 조직학 및 조직병리학을 이론을 삽입하므로 인해 이론과목이 높게 나타났다. 다만 임상 병리사 국가시험에서 실습 시험이 없는 임상생리학(이론에 일 부 포함)의 경우 임상실습이 1:2로 나타나 실습의 비중이 높음 을 알수 있었다. 이번 교육과정의 분석을 통해 3 년제 대학의 교 육과정은 임상병리사 국가시험위주의 교육과정의 편성을 파악 할수 있었다. 그러나 현재 임상병원에서 중요시 되는 분자생물 학분야, 특수검사분야 등을 전혀 반영하지 못하고 있는 점은 앞 으로 교육과정 개발에 있어서 개선해야 할 것으로 사료된다. 4 년제 교육과정은 미래변화를 반영한 과목이 다양하게 개설되어 있었지만 일부 대학에 불과했다. 또한, 자율적인 수강신청으로 전공과목 중 학생들이 어렵게 여기는 과목에 대해서는 수강하 지 않고서도 국가시험을 볼수 있는 문제점이 발견되었다. 같은 면허인데 교육과정에 있어서 질적으로도 차이가 있고 양적으로 도 차이가 있으며, 4 년제의 경우 전공이외에 시대가 요구하는 교양과 다양한 취업처로 진출하기 위한 교과목과 급변하는 4차 산업혁명에 연관된 교과목 이수의 기회가 높다. 결과적으로 우 수한 전문성과 미래변화에 대비할 수 있는 교육을 위해 표준교 육과정이 하루 빨리 필요하다고 생각되며 이를 위한 협회와 대 학에서 임상병리교육평가원 설립 및 운영을 위한 노력이 더욱 요구된다. 다양한 기관에서 임상실습교육을 실시하고 있는 현 실에서 실습교육의 실시와 평가의 전체 과정에서 자연스럽게 일관성을 갖추기는 현실적으로 불가능하므로 이에 대한 인위적 인 표준화작업이 수반되어야 한다는 결론이 도출되었다. 현재 교수회와 협회에서 임상병리학교육평가원의 설립이 추진되고 있는 시점에서 교육과정 및 교육성과에 대한 준거, 시행세칙, 판 단근거 등을 설정할 때 본 연구의 기초자료를 활용하여 임상실 습교육에 대한 표준화방안을 함께 제시하는 것이 합리적 접근 방법이라고 사료된다. 외국 교육과정의 문헌조사 결과 나라마 다 임상병리사에 대한 교육수준의 요구정도는 차이점을 보임을 알 수 있었고, 우리나라의 경우에는 3년제 전문학사와 4년제 학 사학위로 구분되어 운영되고 있지만 임상현장에서 업무의 차이 나 대우의 차이는 거의 없는 것이 현실이다. 우리나라의 의학, 보건의료기술이 빠른 변화를 보이며 발전해 나가고 있는 현실 을 감안한다면 4년제 과정을 통해 좀 더 전문적인 임상병리사를 배출하는 것이 앞으로의 우리나라 현실에 적합한 교육과정운영 이 될 수 있을 것이라고 생각된다.

\section{요 약}

본 연구는 임상병리사의 3년제 교육과정, 4년제 교육과정, 임상실습현황, 해외 교육과정 및 실습을 조사 분석하여 급변하 는 우리나라의 임상병리분야에 대처할 수 있는 정책의 기초 자 료를 제공하고자 하였다. 교육커리큘럼의 분석은 3년제 25 개 대학 및 4년제 25개 대학의 2017학년도 기준 교육과정을 요청 하여 전수 조사하였다. 임상실습은 설문조사를 실시하여 대학 76 건, 산업체 1142 건을 분석하였다. 교육과정의 분석결과 3 년 제 대학의 교육과정은 임상병리사 국가시험위주의 교육과정의 편성을 파악할 수 있었으며, 4 년제 교육과정은 미래변화를 반영 한 과목이 다양하게 개설되어 있었지만 일부 대학에 불과했다. 또한, 자율적인 수강신청으로 전공과목 중 학생들이 어렵게 여 기는 과목에 대해서는 수강하지 않고서도 국가시험을 볼 수 있 는 문제점이 발견되었다. 임상실습의 경우 다양한 실습기관과 실습시기, 실습학점으로 현실적으로 표준화가 어려운 것이 실 정이었다. 실무중심의 교육을 위하여 교내실습교육도 강화되 어야 하겠지만, 현장에서의 실무교육 또한 중요하므로 임상실 습의 기간과 교육시간에 따른 학점의 편성이 표준화되고, 적절 하게 산출되어야 할 필요가 있을 것이다. 임상병리사 직무분석 및 임상현장을 고려하여 현장실무형 교육과정 개정이 필요하 며, 이는 임상병리사평가원을 통해 교육과정과 임상실습모델 의 표준화 작업이 필요할 것으로 생각된다.

Acknowledgements: This work was supported by the Korean Association Medical Technologist research fund (2017).

Conflict of interest: None

\section{REFERENCES}

1. Hwang SC, Lee CK, Song JO. Extension of school years and revision of curriculum for the medical laboratory science education. Korean Journal of Medical Technologists. 1989;21: 201-230.

2. Kim HS, Kwon PS, Kang JH, Yang MG, Park JO, Kim DJ, et al. Survey on the education system and national licensing examination for fostering competent medical technologists. Korean J Clin Lab Sci. 2017;49:161-170.

3. Song JH, Park SY, Choe YH. Analysis of curricular between junior nursing collage program and baccalaureate program for unification of nursing education. Korean Nurse. 1994;33:76- 93.

4. Ryang YS, Kim HE, Shin IS. A comparative study of medical technology curricula with special reference to 4 year university programs. Korean J Clin Lab Sci. 1987;19:43-54. 
5. Jekal SJ, Yang MG, Lee SH, Kim DJ, Joo SI, Park JO, et al. Research on policy proposals for training and empowering excellent medical technologists. Seoul: Korea Health Personnel Licensing Examination Institute; 2017. Report No. RE021710-10.

6. ASCP. Board of certification [Internet]. Chicago: American Society for Clinical Pathology; 2017 [cited 2018 June 25]. Available from: https://www.ascp.org/content/board-of-certification.

7. NAACLS. Find a program [Internet]. Rosemont: National Accrediting Agency for Clinical Laboratory Sciences; 2016 [cited 2018 June 25]. Available from: https://www.naacls.org/ Finda- Program. aspx?program.

8. University of Minnesota. Medical laboratory sciences [Internet]. Delaware: University of Minnesota; 2018 [cited 2018 June 25]. Available form: https://www.alliedhealth.umn.edu/medicallaboratory- sciences.

9. University of Conneticut. Medical laboratory sciences [Internet]. Storrs: University of Conneticut; 2018 [cited 2018June 25]. Available form: https://tme.uconn.edu/explore-majors/profiles/mls/.

10. Arkansa State University. Clinical laboratory sciences [Internet]. Jonesboro: Arkansa State University; 2018 [cited 2018 June 25]. Available form: https://www.astate.edu/college/conhp/ departments/clinical-laboratory-sciences/index.dot.

11. Illinois State University. Medical laboratory science [Internet]. Saint Normal: Illinois State University; 2018 [cited 2018 June 25]. Available form: https://healthsciences.illinoisstate.edu/ lab-science/.

12. Emory University Hospital. Emory healthcare medical laboratory science program [Internet]. Atlanta: Emory University Hospital; 2018 [cited 2018 June 25]. Available form: http://www. emoryhealthcare.org/careers/medical-technology.html.
13. University of Texas MD Anderson Cancer Center. Clinical laboratory science [Internet]. Houston: University of Texas MD Anderson Cancer Center; 2018 [cited 2018 June 25]. Available form: https://www.mdanderson.org/education-training/degreesprograms/school-of-health-professions/academics/clinicallaboratory-science.html.

14. CSMLS. Medical Laboratory Technologists [Internet]. Hamilton: Canadian Society of Medical Laboratory Science; 2017 [cited 2018 June 28]. https://www.csmls.org/Medical-LaboratoryProfessionals/About/Medical-Laboratory-Technologists-(MLT). aspx.

15. British Columbia Institute of Technology. Medical laboratory science [Internet]. Burnaby: British Columbia Institute of Technology; 2018 [cited 2018 June 28]. Available form: https://www.bcit.ca/study/programs/6580diplt.

16. Nothern Alberta Institute of Technology. Medical laboratory technology [Internet]. Edmonton: Nothern Alberta Institute of Technology; 2018 [cited 2018 June 25]. Available form: http://www.nait.ca/program_home_77664.htm.

17. AIMS. Medical Laboratory Scientist [Internet]. Milton: Australian Institute of Medical Science; 2018 [cited 2018 June 29]. Available form: https://www.aims.org.au/services/assessmentoptions/medical-laboratory-scientist.

18. Charles Darwin University. Medical laboratory science [Internet]. Casuarina: Charles Darwin University; 2018 [cited 2018 June 29]. Available form: https://www.cdu.edu.au/pcs/medicallaboratory-science.

19. Griffith University. Medical laboratory science [Internet]. Nathan: Charles Darwin University; 2018 [cited 2018 June 29]. Available form: https://www.uac.edu.au/undergraduate/courses/ gu/283322.shtml. 